\title{
Non-obstetric surgery during pregnancy - an eleven-year retrospective analysis
}

\author{
J. Vujic ${ }^{1}$, K. Marsoner ${ }^{1}$, A. H. Lipp-Pump², P. Klaritsch² ${ }^{2}$ H. J. Mischinger ${ }^{1}$ and P. Kornprat ${ }^{*}$ (D)
}

\begin{abstract}
Background: Diagnosis and management of non-obstetric abdominal pathologies during pregnancy are clinically challenging for both obstetricians and general surgeons. Our aim was to evaluate the outcome of pregnant patients who had undergone non-obstetric abdominal surgery.

Methods: We retrospectively reviewed 76 pregnant patients who had required surgery for non-obstetric abdominal pathologies during pregnancy at our department from January 2005 to December 2015. Data were collected retrospectively from medical records as well as from our institutional perinatal database. We evaluated data for clinical presentation, perioperative management, preterm labor, and maternal and fetal outcomes.

Results: The patients' mean age was 29 (interquartile range IQR 25-33) years. Indications for surgery were acute appendicitis in 63\%, adnexal pathology in 11\%, cholecystolithiasis in 5\% and other indications in $21 \%$; surgery was performed in an elective setting in $18 \%$ and in an emergent/urgent setting in $82 \%$. In five cases, complications, three of them oncological, called for further surgery. Ninety-seven percent of operations were conducted under general anesthesia. Median skin-to-skin time was 50 (37-80) minutes, median in-hospital stay was 4 (3.5-6) days, and $5 \%$ required postoperative intensive care. Preterm labor occurred in 15\%, miscarriage in $7 \%$ (none of them directly related to abdominal surgery).
\end{abstract}

Conclusion: Abdominal surgery for non-obstetric pathology during pregnancy can be performed safely, if mandatory, without increases in maternal and fetal pathology, miscarriage, and preterm birth rates.

Keywords: Nonobstetric surgery, Pregnancy, Appendicitis, Cholecystitis, Obstetrics

\section{Background}

Diagnosis and management of non-obstetric abdominal pathologies during pregnancy are clinically challenging for both obstetricians and general surgeons. The number of patients requiring surgical intervention for non-obstetric indications ranges from $0.75-4.8 \%$ [1-3] in retrospective series. Obviously, all published data on non-obstetric surgery in the pregnant patient originate from retrospective case series and a few meta-analyses; no randomized trials are available for this special patient collective and its optimal clinical management. In 2016, Norwitz and coworkers proposed guidelines for the optimized management of the pregnant patient undergoing non-obstetric surgery based on a recent review of observational studies, extrapolation from trials during cesarean delivery, and expert opinions [4].

\footnotetext{
* Correspondence: peter.kornprat@medunigraz.at

${ }^{1}$ Department of General Surgery, Medical University of Graz,

Auenbruggerplatz 29, A-8036 Graz, Austria

Full list of author information is available at the end of the article
}

The most frequent indications for surgery during pregnancy are infections such as acute appendicitis and cholecystitis [5-14]; pregnant women may also require acute surgical intervention for ovarian disorders and bowel obstruction, as well as for traumatological or oncological indications [11]. Any kind of pathology can occur in pregnant women and require immediate surgical treatment and optimized interdisciplinary management to achieve maximum safety for both mother and fetus, to avoid teratogenous medication, fetal acidosis and hypoxemia, and adverse pregnancy outcomes such as miscarriage, stillbirth or premature birth $[4,8]$.

There are no clear recommendations as to the circumstances in which laparoscopy should be used in pregnant women or open surgery preferred; this decision is mostly taken at the surgeon's discretion. Only for unclear acute abdomen with suspected acute appendicitis does the Society of American Gastrointestinal Endoscopic Surgeons recommend laparoscopy $[12,13]$. 
We aimed to evaluate the outcome of pregnant patients undergoing non-obstetric abdominal surgery at our department.

\section{Methods}

Our patient collective was a reference group of 76 pregnant patients who underwent surgery for non-obstetric abdominal pathologies at our department from January 2005 to December 2015. Data were collected retrospectively from medical records as well as from our institutional perinatal database. Surgical technique: Elective surgeries were delayed to the second trimester, whenever possible. If there was an elective indication for surgery during the second or third trimester, surgery was postponed until after delivery; in selected cases, nonobstetric surgery was performed during elective cesarean section. Acute surgical interventions, mostly for infectious surgical indications such as appendicitis and cholecystitis, were performed irrespective of gestational age.

Anesthesia was performed according to standard procedures for adult patients; the fetal heart rate was always documented pre- and postoperatively. When feasible in the operative setting, the fetal heart rate was monitored continuously after the 24th week of pregnancy. Intraoperative tocolysis was administered intravenously in 17 Patients via continuous perioperative infusion with Hexoprenalin $\left(\right.$ Gynipral $\left.^{\circ}\right)$ and in some cases Atosiban (Tractocile ${ }^{\circ}$ after the 24th pregnancy week. The Atosiban (Tractocile ${ }^{\circ}$ ) is in clinical usage since February 2000, and was used in our study in four cases. In other 12 cases tocolysis was performed with Hexoprenalin $\left(\right.$ Gynipral $\left.^{\circ}\right)$.

In advanced pregnancy, non-obstetric surgery was performed in the gynecological operating theater with a caesarian section team on standby.

\section{Results}

The mean age of the 76 patients included in the retrospective analysis of the 11-year period was 29 (interquartile range IQR 25-33) years (Table 1). The predominant indication for non-obstetric surgery was acute appendicitis in $63 \%$, adnexal pathology in $11 \%$, cholecystolithiasis in $5 \%$, and other indications in $21 \%$. Surgical interventions were elective in $18 \%$ (14 patients) of the cases and emergent in $82 \%$ (62 patients). Surgical reintervention was necessary in five (7\%) cases to secure a successful result, and in three cases for oncological reasons. Ninety-seven percent of operations were conducted under general anesthesia. Depending on the type of surgery and individual case, preoperative prophylactic antibiotics were administered to 44 (56\%) of our patients, while $16(22 \%)$ of the patients required therapeutic antibiotics (Table 1). Glucocorticoids were administered $24-48 \mathrm{~h}$ before the surgery in only 6 of the cases as support for fetal lung maturation only if the intervention occurred between the
Table 1 General study data

\begin{tabular}{ll}
\hline Study data & $\mathrm{n}(\%)$, overall: $n=76 /$ median (IQR) \\
\hline Age (Years) & $29(25-33)$ \\
OP time (min) & $50(37-80)$ \\
Appendectomy & $48(63 \%)$ \\
Cholecystectomy & $4(5 \%)$ \\
Other surgical interventions & $16(21 \%)$ \\
Ovarian surgery & $8(11 \%)$ \\
Elective surgery & $14(18 \%)$ \\
Urgent surgery & $44(58 \%)$ \\
Emergency surgery & $18(24 \%)$ \\
Laparoscopic surgery & $19(25 \%)$ \\
Preoperative antibiotics & $44(56 \%)$ \\
Therapeutic antibiotics & $16(22 \%)$ \\
\hline
\end{tabular}

24th and 34th weeks of pregnancy, and only in the absence of systemic infection. Median skin-to-skin time was 50 (37-80) minutes. Intraoperative tocolysis was administered in 17 patients $(22 \%)$. The median hospital stay at our department of general surgery was 4.5 days (4-6). Five percent of patients required postoperative intensive care (Table 2). The gestational age during which most (58\%) of the non-obstetric surgical interventions were performed was the second trimester; 17 of our surgical interventions (22\%) were in the third trimester (Table 3).

After follow-up of patients who had non-obstetric surgical interventions during pregnancy, it was noted that the median pregnancy week reached after the intervention was 40 (37-41). The details of the follow-up are shown in Table 3. Preterm labor occurred in 12 cases (16\%), and miscarriage in 5 cases $(7 \%)$, with none of them directly related to abdominal surgery. In fact, the follow-up documented no case of neonatal mortality, and $9(12 \%)$ cases of neonatal morbidity. Spontaneous birth was reported as most frequent, with 24 cases (32\%). Caesarian section was primary in $18(24 \%)$ cases, and secondary in $13(17 \%)$ cases. Caesarian delivery was performed in the department of surgery in 7 (9\%) patients.

As acute appendicitis is the most common nonobstetrical surgical intervention during pregnancy, special attention was paid to the detailed data of this predominant group of patients (48 of 76 cases). The detailed data on the appendectomy cohort is presented in Table 4 . The prevalent operational approach was open appendectomy in 42 cases, while a laparoscopic approach was used in only 6 cases. The two-sided $p$ value showed that there were no consequences for gestational week at birth (mean value 4 and 39). Antibiotic therapy was administered only in open appendectomy in 11 cases (28\%). Glucocorticoids were also administered only in open appendectomy in 2 cases (5\%). Of the patients who underwent open appendectomy, two showed perioperative morbidity (5\%) and three had 
Table 2 Intra- and postoperative data

\begin{tabular}{ll}
\hline Intraoperative data & $\mathrm{N}(\%)$, overall $n=76$ \\
\hline Intervention in general anesthesia & $74(97 \%)$ \\
Local/spinal anesthesia & $\begin{array}{l}4(5 \%)^{\mathrm{a}} \text { Conversion to general } \\
\text { anesthesia in } 2 \text { cases }\end{array}$ \\
Intraoperative tocolysis & $17(22 \%)$ \\
Postoperative maternal complications & $4(5 \%)$ \\
Postoperative fetal complications & $5(7 \%)$ \\
Postoperative ICU stay (days) & $4(5 \%)$ \\
Surgical reintervention & $5(7 \%)$ \\
Preoperative glucocorticoids & $6(8 \%)$ \\
OP 1st trimester & $15(20 \%)$ \\
OP 2nd trimester & $44(58 \%)$ \\
OP 3rd trimester & $17(22 \%)$ \\
Gestational age (weeks) & $18.5(14-25)$ \\
Hospital stay (days) & $4(3.5-6)$ \\
\hline
\end{tabular}

* conversion to general anesthesia in 2 cases

three miscarriages (7\%). There was no statistically significant difference in lengths of hospital stay for patients who had open or laparoscopic appendectomy (mean value 4 and 5.5) (Table 4).

\section{Discussion}

Non-obstetric acute abdomen during pregnancy can be a diagnostic and therapeutic challenge. Pregnancy can obscure the clinical diagnosis; the perfomance of clinical examinations is still controversial [6], and the debate on the safest surgical approach during pregnancy continues.

The diagnosis of acute appendicitis is based mainly on the history and physical examination, which is less reliable in pregnant women, who undergo pathophysiological changes that favor relative immune suppression, thus altering the inflammatory response $[4,5,9$, $14,15,16$,]. The diagnosis of acute abdomen for nonobstetric complications (mostly appendicitis or

Table 3 Follow-up with pregnancy outcome details

\begin{tabular}{ll}
\hline Outcome details & $\mathrm{N}(\%)$, median (IQR) \\
\hline Miscarriage & $5(7 \%)$ \\
Gestational age at delivery & $40(37-41)$ \\
Premature birth & $12(16 \%)$ \\
Spontaneous birth & $24(32 \%)$ \\
Vaginal-surgical & $4(5 \%)$ \\
Secondary Caesarean & $13(17 \%)$ \\
Primary Caesarean & $18(24 \%)$ \\
Caesarean in non-obstetrical department & $7(9 \%)$ \\
Neonatal morbidity & $9(12 \%)$ \\
Neonatal mortality & 0 \\
Maternal mortality & 0 \\
\hline
\end{tabular}

cholecystitis) is performed using ultrasound and magnetic resonance imaging (MRI). Ultrasonography (USG) has a reported sensitivity of $67-100 \%$ and specificity of $83-96 \%$ for appendicitis in pregnancy. MRI is most meaningful in identification of a non-pathological appendix, thereby ruling out inflammation [15]. According to American College of Radiology, it is less reliable in detecting the presence of extraluminal air in perforated intestine, and therefore placed as second line imaging diagnostic method in this case [15]. In accordance with published studies, in our patient collective, acute appendicitis was the predominant reason for nonobstetric abdominal surgery during pregnancy $[6,14]$. Complicated forms of acute appendicitis are reported to be more frequent in pregnant women and are associated with obstetrical complications such as premature delivery [4-6]. In our total collective, there were 12 premature births $(16 \%)$, of which only $4(10 \%)$ occurred after open appendectomy (none of which was characterized as complicated). Gök et al. suggested in their study that there is no significant difference in fetal or maternal outcome after open appendectomy and laparoscopic appendectomy [16]. The results of our study confirm their claim that both methods are safe, and that neither method led to fetal or maternal mortality [10]. Follow-up revealed no complications for either approach that were directly related to a negative pregnancy outcome.

The second most common reason for surgical intervention during pregnancy in our study was adnexal pathology, including one case of pediculated leiomyoma, the third was cholecystolithiasis [17-25].

Symptomatic gallstone disease in pregnancy has been reported to be related to increased mortality risk for both the mother and fetus $[17,20]$. Cholecystolithiasis was diagnosed by using ultrasound (USG). USG is the diagnostic method of choice with a sensitivity of more than 95\% [15]. Authors such as Sachs et al. stratified the risks of undergoing appendectomy and cholecystectomy in pregnancy, and concluded that approximately $5 \%$ of women experienced adverse obstetrical outcomes after appendectomy or cholecystectomy during pregnancy [2]. They found that cervical incompetence, sepsis, and other pre-existing states influenced adverse pregnancy outcomes, but not the surgical approach itself. These findings are in line with our results showing that surgical intervention had no influence on pregnancy outcome. Barut et al. and others have concluded that although conservative management of acute cholecystitis was favored, early surgical intervention showed better results [7]. Cholecystectomy was performed in our study in 4 cases $(5 \%)$, without adverse effects on pregnancy.

Problems related to general anesthesia for nonobstetric interventions during pregnancy could be prevented by avoiding potentially dangerous drugs and securing adequate 
Table 4 Appendectomy data

\begin{tabular}{|c|c|c|c|c|}
\hline Variable & $\begin{array}{l}\text { Total cohort appendectomy } \\
(n=48), \mathrm{n}(\%), \text { median (IQR) }\end{array}$ & Open AE $(n=42)$ & Lap. AE $(n=6)$ & Two-sided $p$-value \\
\hline Age (years) & $29(25-33)$ & $29(25-33)$ & $32(27-35)$ & 0.35 \\
\hline OP time (minutes) & $42(35-57)$ & $42(35-53)$ & $50(38-87)$ & 0.32 \\
\hline Gestational week at surgery (weeks) & $18(12-21)$ & $19(15-23)$ & $12(10-18)$ & 0.05 \\
\hline Gestational week at birth & $40(38-41)$ & $40(38-40)$ & $39(39-41)$ & 0.47 \\
\hline Birth weight (g) & $3330(2918-3618)$ & $3270(2902-3560)$ & $3400(3214-3586)$ & 0.12 \\
\hline Tocolysis & $10(21 \%)$ & $10(24 \%)$ & 0 & 0.32 \\
\hline Antibiotic therapy & $11(24 \%)$ & $11(28 \%)$ & 0 & 0.31 \\
\hline Glucocorticoids & $2(4 \%)$ & $2(5 \%)$ & 0 & 1 \\
\hline Preterm birth ${ }^{a}$ (13/48 Birth not at the Clinic) & $4(8 \%)$ & $4(10 \%)$ & 0 & 0.35 \\
\hline Maternal perioperative morbidity & $2(4 \%)$ & $2(5 \%)$ & 0 & 1 \\
\hline Miscarriage & $3(6 \%)$ & $3(7 \%)$ & 0 & 1 \\
\hline Hospital stay (days) & $4.5(4-6)$ & $4(3.75-5)$ & $5.5(4.5-6)$ & 0.238 \\
\hline
\end{tabular}

* 13/48 birth not at the clinic

uteroplacental perfusion [3]. Up to now, no anesthetic drug has been shown to be clearly dangerous to the human fetus [21]. The decision on proceeding with surgery should be made by multidisciplinary team involving anesthesiologists, obstetricians, surgeons and perinatologists [8]. In our study, 74 (97\%) of surgical interventions were performed in general anesthesia, with 4 cases of local/spinal anesthesia, of which 2 were converted to general anesthesia. Postoperative maternal complications developed in 4 cases (5\%), with a mean ICU stay of 4 days, indicating the safety of general anesthesia. The American College of Obstetricians and Gynecologists published guidelines that proposed imperative consultation with obstetricians prior to nonobstetric surgery and other invasive procedures (e.g., coronary angiography or colonoscopy) because obstetricians are uniquely qualified to discuss aspects of maternal physiology and anatomy that may affect intraoperative maternal and fetal well being [8].

The study of Fong et al. focused on surgical interventions during the third trimester of pregnancy, giving the general recommendation that they should be avoided whenever possible [20]. In our study, 22\% (17 cases) of all interventions were made the in third trimester, and went without significant complications. Yu et al. reported that an unfavorable pregnancy outcome after non-obstetric surgical intervention during pregnancy is based predominantly on inflammatory reaction and scar formation after nonobstetric surgery and postoperative hemorrhaging, none of which we found our study [1]. We reported 6 cases in which preoperative glucocorticoids could control the inflammatory response; the remaining 70 cases (92\%) received no drugs preoperatively that could influence the inflammatory response, but without any significant adverse effect on postoperative complications. Huang et al. suggested that pregnant patients undergoing abdominal surgery showed more adverse events, with a slightly elevated risk of in-hospital mortality after nonobstetric surgery, than did nonpregnant patients [18]. These findings suggest a need to revise the protocols for postoperative care. None of the premature labors or miscarriages in our study was directly connected to surgical intervention. There is general agreement that surgical intervention should be performed in pregnant women whenever indicated; to our knowledge, there is no published report recommending general avoidance of surgical intervention during pregnancy, except for some recommendations concerning interventions in the third trimester $[11,14]$. Further research on non-obstetric surgical interventions in pregnant women is warranted to develop guidelines for optimal pre- and postoperative management in pregnant women.

\section{Conclusion}

Our study indicates that abdominal surgery for nonobstetric pathology during pregnancy can be performed safely whenever indicated without adverse obstetric outcome for either mother or fetus. In our study intraoperative treatment had no adverse influence on maternal or fetal pregnancy outcome.

\section{Abbreviations}

ICU: Intensive care unit; IQR: Interquartile range; MRI: Magnetic resonance imaging; USG: Ultrasonography

\section{Acknowledgments}

None to declare.

\section{Authors' contributions}

The study was designed by PKo, HM, and PKI. PKo, HM, PKI, AL-P, and JV aided the study design. Patient population determination was performed by PKo, PKl, HM, and KM. Data analysis was performed by KM, JV, and AL-P. JV, KM and PKo wrote the manuscript. All authors declare that they participated 
in creation of the study equally and have critically reviewed the manuscript All authors have read and approved the final manuscript.

\section{Funding}

We hereby declare no funds to be received for the study.

\section{Availability of data and materials}

The datasets generated and/or analyzed during the current study are not publicly available due to Patient Data Protection Law (\$37 Datenschutz in der Krankenanstalt, Stmk. Krankenanstaltengesetz 2012, Fassung vom 29.03.2019) but are available from the corresponding author on reasonable request.

\section{Ethics approval and consent to participate}

Since this study was retrospective in nature, the ethics board waived the need for patients' consent to participate and the need for approval. Therefore it was not necessary that patients consented to analysis of their medical records and no further permission from the institution was required.

\section{Consent for publication}

Not applicable.

\section{Competing interests}

All authors declare that they have no conmpeting interests or financial interests that could affect this study.

\section{Author details}

'Department of General Surgery, Medical University of Graz, Auenbruggerplatz 29, A-8036 Graz, Austria. ${ }^{2}$ Department of Gynecology and Obstetrics, Medical University of Graz, Graz, Austria.

Received: 30 June 2019 Accepted: 2 October 2019

Published online: 25 October 2019

\section{References}

1. Yu CH, Weng SF, Ho CH, Yu CH, et al. Pregnancy outcomes following nonobstetric surgery during gestation: a nationwide population-based casecontrol study in Taiwan. BMC Pregnancy and Childbirth. 2018;18:460.

2. Sachs A, Guglielminotti J, Miller R. Risk factors and risk stratification for adverse obstetrical outcomes after appendectomy or cholecystectomy during pregnancy. JAMA Surgery. 2017;152(5):436. https://doi.org/10.1001/ jamasurg.2016.5045

3. Longinus EN, Chinwe $\mathrm{O}$, Yvone $\mathrm{BO}$. Case report: the obstetric patient going for non-obstetric surgery. Jos J Med. 2012;6:3.

4. Norwitz ER, Park JS, Snegovskikh D. Management of the pregnant patient undergoing nonobstetric surgery (Wolters Kluwer); 2016-2019.

5. El Ghali MA, Kaabia O, Mefteh ZB. Acute appendicitis complicating pregnancy: a 33 case series, diagnosis and management, features, maternal and neonatal outcomes. Pan African Med J. 2018;30:212. https://doi.org/10. 11604/pamj.2018.30.212.14515.

6. Bazdar S, Dehghankhalili M, Yaghmaei S, Azadegan M, Pourdavood AH, Niakan $\mathrm{MH}$, Bananzadeh AM. Acute appendicitis during pregnancy; results of a cohort study in a single Iranian center. Bull Emerg Trauma. 2018;6(2):122-7.

7. Barut B, Gönültaş F, Gök AFK, Şahin TT. Management of acute cholecystitis during pregnancy: a single-center experience. Ulus Travma Acil Cerrahi Derg. 2019;25:154-8

8. Committee on Obstetric Practice American Society of Anesthesiologists. The American College of Obstetricians and Gynecologists. COMMITTEE OPINION on nonobstetric Surgery during Pregnancy, vol. 696; 2017.

9. Chakraborty J, Kong JC, Su WK. Safety of laparoscopic appendectomy during pregnancy: a systematic review and meta-analysis. ANZ J Surg. 2019; 3(3):475. https://doi.org/10.1111/ans.14963.

10. Shigemi D, Aso S, Matsui H. Safety of laparoscopic surgery for benign diseases during pregnancy: a Nationwide retrospective cohort study. Minim Invasive Gynecol. 2018;00:1-6.

11. Upadya M, Saneesh PJ. Anaesthesia for non-obstetric surgery during pregnancy. Indian J Anaesth. 2016;60:234-41.

12. Sooper NJ. SAGES' guidelines for diagnosis, treatment, and use of laparoscopy for surgical problems during pregnancy. Surg Endosc. 2011;25:3477-8.

13. Pearl JP, Price RR, Tonkin AE. SAGES quidelines for the use of laparoscopy during pregnancy 2017. https://www.sages.org/publications/guidelines/ guidelines-for-diagnosis-treatment-and-use-of-laparoscopy-for-surgicalproblems-during-pregnancy/. Accessed Aug 2019.

14. Balinskaite V, Bottle A, Sodhi V. The risk of adverse pregnancy outcomes following nonobstetric surgery during pregnancy. Ann Surg. 2017:266:260-6.

15. Zachariah SK, Fenn M, Jacob K, Arthungal SA, Zachariah SA. Management of acute abdomen in pregnancy: current perspectives. Int J Women's Health. 2019:11:119-34.

16. Gök AFK, Soytaş Y, Bayraktar A, Emirikçi S, Illhan M, Koltka AK, et al. Laparoscopic versus open appendectomy in pregnancy: a single center experience. Ulus Travma Acil Cerrahi Derg. 2018;24:552-6.

17. IIthan M, Illhan G, Gök AFK. The course and outcomes of complicated gallstone disease in pregnancy: experience of a tertiary center. Turk J Obstet Gynecol. 2016;13:178-82.

18. Huang SY, Lo PH, Liu WM. Outcomes after nonobstetric surgery in pregnant patients: a Nationwide study in Taiwan. Mayo Clin Proc. 2016;91(9):1166-72.

19. Schwarzman $P$, Baumfeld $Y$, Bar-Niv Z. The effect of non-obstetric invasive procedures during pregnancy on perinatal outcomes. Arch Gynecol Obstet. 2015;292(3):603. https://doi.org/10.1007/s00404-015-3689-y.

20. Fong ZV, Pitt HA, Strasberg SM. Cholecystectomy during the third trimester of pregnancy: proceed or delay? Am Coll Surg. 2019;228:1-9.

21. Nejdlova $M$, Johnson T. Anesthesia for non-obstetric procedures during pregnancy. Crit Care Pain. 2012:12:203-6.

22. Tankel J, Yellinek S, Shechter Y. Delaying laparoscopic surgery in pregnant patients with an equivocal acute appendicitis: a step-wise approach does not affect maternal or fetal safety. Surg Endosc. 2018;33(9):2960. https://doi. org/10.1007/s00464-018-6600-7

23. Frountzas M, Nikolaou C, Stergios K. Is the laparoscopic approach a safe choice for the management of acute appendicitis in pregnant women? A meta-analysis of observational studies. Ann R Coll Surg Engl. 2019;00:1-16.

24. Baruch $Y$, Canetti $M$, Blecher $Y$. The diagnostic accuracy of ultrasound in the diagnosis of acute appendicitis in pregnancy. J Matern Fetal Neonatal Med. 2019. https://doi.org/10.1080/14767058.2019.1592154.

25. Powell-Bowns M, Wilson MSJ, Mustafa A. Documentation of pregnancy status, gynecological history, date of last menstrual period and contraception use in emergency surgical admissions: time for a change in practice? World J Surg. 2015;39:2849-53.

\section{Publisher's Note}

Springer Nature remains neutral with regard to jurisdictional claims in published maps and institutional affiliations.

Ready to submit your research? Choose BMC and benefit from:

- fast, convenient online submission

- thorough peer review by experienced researchers in your field

- rapid publication on acceptance

- support for research data, including large and complex data types

- gold Open Access which fosters wider collaboration and increased citations

- maximum visibility for your research: over $100 \mathrm{M}$ website views per year

At BMC, research is always in progress.

Learn more biomedcentral.com/submissions 